\title{
Correlation of thermal deficit with clinical parameters and functional status in patients with unilateral lumbosacral radiculopathy
}

\author{
Irena M Dimitrijevic *, Mirjana N Kocic, Milica P Lazovic, Dragan D Mancic, Olga K Marinkovic, \\ Dragan S Zlatanovic
}

\section{A B S T R A C T}

Introduction: Lumbosacral radiculopathy is a pathological process that refers to the dysfunction of one or more spinal nerve roots in the lumbosacral region of the spine. Some studies have shown that infrared thermography can estimate the severity of the clinical manifestation of unilateral lumbosacral radiculopathy. This study aimed to examine the correlation of the regional thermal deficit of the affected lower extremity with pain intensity, mobility of the lumbar spine, and functional status in patients with unilateral lumbosacral radiculopathy.

Methods: This cross-sectional study was conducted at the Clinic for Physical Medicine and Rehabilitation of the Clinical Center Niš, Serbia. A total of 69 patients with unilateral lumbosacral radiculopathy of discogenic origin were recruited, with the following clinical parameters evaluated: (1) pain intensity by using a visual analogue scale, separately at rest and during active movement; (2) mobility of the lumbar spine by Schober test and the fingertip-to-floor test; and (3) functional status by the Oswestry Disability Index. Temperature differences between the symmetrical regions of the lower extremities were detected by infrared thermography. A quantitative analysis of thermograms determined the regions of interest with maximum thermal deficit. Correlation of maximum thermal deficit with each tested parameter was then determined. was found between the regional thermal deficit and pain intensity at rest, as well as pain during active movements $\left(r_{\mathrm{VAS}-\text { rest }}=0.887, r_{\mathrm{VAS}-\text { activity }}=0.890\right.$; $\mathrm{P}<0.001)$. The regional thermal deficit significantly and strongly correlated with the Oswestry Disability Index score and limited mobility of the lumbar spine $(\mathrm{P}<0.001)$.

Conclusions: In patients with unilateral lumbosacral radiculopathy, the values of regional thermal deficit of the affected lower extremity are correlated with pain intensity, mobility of the lumbar spine, and functional status of the patient.

\section{DOI: $10.12809 / \mathrm{hkmj} 154748$

\author{
IM Dimitrijevic *, MSc, MD \\ ${ }^{2} \mathrm{MN}$ Kocic, MD, PhD \\ ${ }^{3}$ MP Lazovic, MD, PhD \\ ${ }^{4}$ DD Mancic, PhD \\ ${ }^{2}$ OK Marinkovic, $M D$ \\ 2DS Zlatanovic, MSc, MD
}

Hong Kong Med J 2016;22:320-6
Department of Rehabilitation of Neurology, Traumatic, Rheumatic Patients and After-surgery States, Institute for Treatment and Rehabilitation "Niška Banja", Niš, Serbia
2 Clinic for Physical Medicine and Rehabilitation, Clinical Center Niš, Niš, Serbia and Faculty of Medicine, University of Niš, Niš, Serbia Institute for Rehabilitation Belgrade, Belgrade, Serbia and Faculty of Medicine, University of Belgrade, Belgrade, Serbia
${ }^{4}$ Department of Electronics, Faculty of Electronic Engineering, University of Niš, Niš, Serbia
* Corresponding author: irenadimitrije@gmail.com

\footnotetext{
New knowledge added by this study

- The values of the regional thermal deficit, especially at the heel and plantar region of the affected foot, significantly and strongly correlated with radicular pain intensity.

- The values of the regional thermal deficit of the affected lower extremity also correlated with limited mobility of the lumbar spine and functional status of patients with unilateral lumbosacral radiculopathy.

Implications for clinical practice or policy

Infrared thermography may be applied for an objective assessment of radicular pain intensity.
}

\section{Introduction}

Lumbosacral radiculopathy is a pathological process that refers to the dysfunction of one or more spinal nerve roots in the lumbosacral region of the spine. It is a frequent consequence of degenerative changes in the intervertebral discs that cause compression of the spinal nerve root in the intervertebral foramen. ${ }^{1}$ The main clinical characteristic of this disease is pain that spreads from the lumbar spine to one of the lower extremities. ${ }^{1}$ In addition, a typical clinical presentation is characterised by sensory deficits, muscle weakness, and impaired deep tendon reflexes. ${ }^{1,2}$ 
The initial diagnosis of radiculopathy is based on a detailed patient history and physical examination. $^{3} \quad$ A precise diagnosis requires information about the function of the spinal nerve root, as well as structural changes in the spine so additional diagnostic procedures are used: electrodiagnostic testing and magnetic resonance imaging (MRI) or computed tomography., ${ }^{2,3}$

There is a possibility of using infrared thermography (IRT) since vasomotor dysfunction caused by irritation or damage of the spinal nerve root leads to abnormal changes in skin temperature of the affected lower extremity.,4-8 Temperature differences between the symmetrical parts of the lower extremities can be detected by IRT. A quantitative analysis of the recorded temperature differences provides information that may indicate unilateral radiculopathy. ${ }^{4,5,7}$ Considering the ability of IRT to estimate vasomotor instability, it can be used to detect unilateral radiculopathy and thus supplement the findings of clinical, morphological, and functional examination. ${ }^{7}$ Some studies have shown that IRT can estimate the severity of the clinical manifestation of unilateral lumbosacral radiculopathy. ${ }^{5,9-11}$

The aim of this study was to examine the correlation of regional thermal deficit of the affected lower extremity with pain intensity, mobility of the lumbar spine, and functional status in patients with unilateral lumbosacral radiculopathy.

\section{Methods}

\section{Patients}

This cross-sectional study included out-patients with lumbosacral radiculopathy who were treated at the Clinic for Physical Medicine and Rehabilitation of the Clinical Center Nišs, Serbia, between February 2012 and January 2013. Clinical Center Niš is a tertiary institution that provides health services for the whole southeast and south Serbia, with a population of around 3 million. Clinical Center Niš is also the educational and scientific research base of the Faculty of Medicine, University of Niš. During the study period, 97 of 213 patients with lumbosacral radiculopathy were recruited. All were aged over 18 years, had symptoms present for more than 6 weeks, and had unilateral clinical manifestations. The diagnosis was made by clinical examination and confirmed by additional investigations such as needle electromyography or MRI. Patients were excluded if they had any of the following: pregnancy, skin changes (lacerations, inflammation, haemangioma), inflammatory joint disease, malignant disease, infectious disease, disorders of peripheral circulation (varicosities, thrombophlebitis), neurological disorder (various neuropathies), spinal stenosis, cauda equina

\section{單側腰骶神經根病患者的紅外熱圖像溫點溫差與 其臨床特徵和功能狀態的相關性}

Irena M Dimitrijevic, Mirjana N Kocic, Milica P Lazovic, Dragan D Mancic, Olga K Marinkovic, Dragan S Zlatanovic

引言: 腰骶神經根病是指脊柱腰骮部一條或多條脊神經根的功能障 礙。一些研究顯示紅外熱圖像可以評估單側腰骮神經根病的嚴重程 度。本研究旨在探討單側腰骶神經根病患者受影響下肢的紅外熱圖像 溫點溫差與其疼痛程度、腰椎可動性和患者功能狀態的相關性。

方法: 這橫斷面研究在塞爾維亞一所物理醫學與復康診所內進行。源 自椎間盤的單側腰筥神經根病患者共有 69 例, 為他們評估以下的臨床 參數：(1) 使用視覺模擬評分測量患者在休息和運動過程中所感受 的疼痛程度; (2) 使用Schober試驗和指尖地板距離量測法測量患者 腰椎的可動性; 和 (3) 使用Oswestry功能障礙指數測量患者的功能 狀態, 並利用紅外熱圖像偵測患者下肢對稱區域之間的溫差以及定量 分析溫譜圖找出感興趣區域的最大溫差, 然後確定每項臨床參數與最 大溫差之間的相關性。

結果：紅外熱圖像溫點溫差與患者在休息 $(r=0.887)$ 和運動過程 $(r=0.890)$ 中所感受的疼痛程度呈顯著強烈正相關 $(\mathrm{P}<0.001)$ 。此 外, 紅外熱圖像溫點溫差與Oswestry功能障礙指數評分和腰椎受限的 可動性呈顯著強烈正相關 $(\mathrm{P}<0.001)$

結論：單側腰骶神經根病患者受影響下肢的紅外熱圖像溫點溫差與其 疼痛程度、腰椎可動性和患者功能狀態相關。

syndrome, bilateral lumbosacral radiculopathy, or previous injury of the lumbosacral region of the spine as well as previous surgical interventions in the same region. Of 97 recruited patients, five refused to participate and 23 patients were excluded due to anamnestic or clinical indicators of the diseases listed in the exclusion criteria. A total of 69 patients with unilateral lumbosacral radiculopathy of discogenic origin were eligible for the study.

The study was approved by the Ethics Committee of the Faculty of Medicine, University of Niš (no. 01-6481-2). All patients gave written consent to participate in the study.

\section{Clinical and functional evaluation}

We measured the following parameters by clinical examination:

(1) Pain intensity was measured on a visual analogue scale (VAS). This scale represents a 10 - $\mathrm{cm}$ horizontal scale, graded 0 to 10 , where 0 is a condition without pain and 10 is the worst possible pain. ${ }^{12}$ Pain intensity was measured separately at rest and during active movement of the lumbar spine. The patients marked their pain intensity on VAS as an average value of the pain they had experienced for 7 days before the test. 
(2) The mobility of the lumbar spine was tested by (a) fingertip-to-floor distance (FFD) that refers to measuring the flexion of the lumbar spine as a distance from the tip of the middle finger to the floor, expressed in centimetres ${ }^{13}$ and (b) the Schober test that assesses the mobility by measuring changes in the distance between the two spinal marks. Spinal marks were made on the skin at the spinous process of L5 and $10 \mathrm{~cm}$ above when a patient stood in a neutral position. The patient then bent forward with straight knees and the change in distance between these marks is measured in centimetres. ${ }^{14}$ The investigator, who was blinded to the results of other assessments, tested the mobility of the lumbar spine.

(3) The functional ability of patients was estimated by the Oswestry Disability Index (ODI) that comprises 10 questions. Each question has six given answers that are graded 0 to 5 points. After completing the questionnaire, the points were added and expressed in percentages with respect to the maximum number of points (50), where a higher value corresponds to more severe functional disability. ${ }^{15}$

The participants filled in the questionnaire in their native language, without any assistance from the investigators.

\section{Infrared thermographic imaging}

The examined patients were recorded by infrared (IR) imaging camera and the thermograms were quantitatively analysed. The operator, who recorded and analysed the thermograms, did not know the nature of the patient's disease. In this study, only one set of recordings was used, according to the recommendation of the guidelines for neuromusculoskeletal thermography that a single set of thermograms can be adequate in cases where obvious temperature asymmetry exists. ${ }^{16}$

The conditions of thermographic recording were the same for all patients, according to the guidelines for neuromusculoskeletal thermography of the American Academy of Thermology. ${ }^{16}$ Room temperature, where the recordings were conducted, was always within the range of $20^{\circ} \mathrm{C}$ to $25^{\circ} \mathrm{C}$. The room was protected from direct ultraviolet exposure and air conditioning was turned off. Local application of analgesics and cosmetic preparations were avoided before the recording. Corticosteroids, sympathetic blockers, vasoactive medications, and transdermal patches were not used for at least 24 hours before the recording. Physical procedures were not conducted at least 12 hours before and electrodiagnostic testing 24 hours before the recording. ${ }^{16}$

The body part marked as the region of interest (ROI) was without clothes for at least 15 minutes prior to recording. The ROIs were the front and back part of the lower extremity, and plantar area of the foot and the heel. During the recording of the plantar surface of the foot, patients were seated with legs in the horizontal plane and feet in a vertical plane without touching each other. The recording of the lower extremity was done with patients in a standing position with lower extremities in slight abduction. A varioSCAN high-resolution 3021 imaging camera (Jenoptik, Dresden, Germany) recorded bilateral ROIs. The analysis of the thermograms was done by IRBIS Professional 2.2. graphic-oriented software package (InfraTec GmbH, Dresden, Germany).

Quantitative analysis of the thermograms determined the average temperature value of ROIs, expressed in degrees Celsius. For each patient and for each separate ROI, a difference in average temperature value was calculated, between ROI of unaffected and affected lower extremity, according to the formula:

$\Delta \mathrm{T}=$ mean value temperature ROI of unaffected lower extremity - mean value temperature ROI of the affected extremity

In order to correlate regional thermal deficit $(\Delta \mathrm{T})$ with other examined parameters, ROI with maximum $\Delta \mathrm{T}(\max \Delta \mathrm{T})$ value was considered.

In the final stage of the research, a correlation analysis of max $\Delta \mathrm{T}$ and each separate tested parameter was performed.

\section{Statistical analysis}

Data were analysed using the Statistical Package for the Social Sciences (Windows version 10.0; SPSS Inc, Chicago [IL], US). Normal distribution was tested by Kolmogorov-Smirnov test. The results of the statistical analysis were represented as mean \pm standard deviation for data with normal distribution, or as median for data without normal distribution. In order to test the correlation between max $\Delta \mathrm{T}$ and other tested parameters, Pearson correlation coefficient $(r)$ was used for normal distribution or Spearman correlation coefficient $(\rho)$ for data without normal distribution. A P value of $<0.05$ was considered statistically significant.

\section{Results}

Baseline characteristics of patients are shown in Table 1. Thermogram of the lower extremities showed a significant thermal deficit $\left(\Delta \mathrm{T}>1^{\circ} \mathrm{C}\right)$ in the affected lower extremity in at least one out of four recorded ROIs. In the majority of patients $(n=43$; $62.3 \%$ ), maximum $\Delta \mathrm{T}$ value was obtained at the heel or plantar region of the foot. Outcome measures are shown in Table 2 as mean value for parameters with normal distribution and median value with interquartile range for parameters without normal distribution.

A statistically significant and strong positive 
correlation was found between $\max \Delta \mathrm{T}$ and pain intensity at rest (VAS - rest), as well as pain during

TABLE I. Baseline characteristics of patients

\begin{tabular}{lc}
\hline Characteristic & Data* $^{*}$ \\
\hline Age (years) & $53.75 \pm 10.14$ \\
Gender (male / female) & 32 / 37 \\
Body mass index $\left(\mathrm{kg} / \mathrm{m}^{2}\right)$ & $26.97 \pm 3.80$ \\
Smoking (yes / no) & $29 / 40$ \\
\hline
\end{tabular}

* Data are shown as mean \pm standard deviation or No. of patients

TABLE 2. Assessment of pain, regional temperature difference, mobility of the lumbar spine, and functional status

\begin{tabular}{lc}
\hline Outcome & Data $^{*}$ \\
\hline Pain - rest (VAS) & $5.58 \pm 1.80$ \\
Pain - activity (VAS) & $6.40 \pm 1.86$ \\
$\Delta \mathrm{T}$ - anterior calf $\left({ }^{\circ} \mathrm{C}\right)$ & $0.70 \pm 0.31$ \\
$\Delta \mathrm{T}$ - posterior calf $\left({ }^{\circ} \mathrm{C}\right)$ & $0.83 \pm 0.39$ \\
$\Delta \mathrm{T}-$ plantar surface $\left({ }^{\circ} \mathrm{C}\right)$ & $0.96 \pm 0.41$ \\
$\Delta \mathrm{T}-$ heel area $\left({ }^{\circ} \mathrm{C}\right)$ & $0.82 \pm 0.56$ \\
$\mathrm{ROI}-$ max $\Delta \mathrm{T}\left({ }^{\circ} \mathrm{C}\right)$ & $1.30 \pm 0.27$ \\
ODI (\%) & $52.75 \pm 10.14$ \\
FFD (cm) & $23.00(21-27)$ \\
Schober test $(\mathrm{cm})$ & $3.5(3-4)$ \\
\hline
\end{tabular}

Abbreviations: FFD = fingertip-to-floor distance; $O D I=$ Oswestry Disability Index; $\mathrm{ROI}-\max \Delta \mathrm{T}=$ region of interest with $\max \Delta \mathrm{T} ; \Delta \mathrm{T}=$ regional side-to-side temperature difference; VAS = visual analogue scale

* Data are shown as mean \pm standard deviation or median (interquartile range) active movement (VAS - activity), and showed that pain intensity (VAS - rest and VAS - activity) increased along with increased value of $\max \Delta \mathrm{T}$ $\left(r_{\mathrm{VAS}-\text { rest }}=0.887, r_{\mathrm{VAS}-\text { activity }}=0.890 ; \mathrm{P}<0.001\right)$.

It has also been determined that there was a significant and strong positive correlation between $\max \Delta \mathrm{T}$ and ODI score that indicates a relationship between these two parameters in that the functional condition of the patient worsened with increased $\max \Delta \mathrm{T}(r=0.744 ; \mathrm{P}<0.001)$.

Furthermore, a statistically significant and strong correlation was evident between max $\Delta \mathrm{T}$ and limited mobility of the lumbar spine. Nonetheless, it should be emphasised that the correlation between $\max \Delta T$ and FFD was positive $(\rho=0.776 ; P<0.001)$ whereas the correlation between $\max \Delta \mathrm{T}$ and Schober test was negative $(\rho=-0.795 ; \mathrm{P}<0.001)$. The relationship between these parameters showed that the mobility of the lumbar spine was reduced with increased value of max $\Delta \mathrm{T}$. Scatter plots show the results of correlation analyses (Figs 1 to 3 ). Thermograms of two patients with different values of thermal deficit are shown in Figure 4.

\section{Discussion}

The results of this study show that regional thermal deficit, determined by thermography, is correlated with pain intensity, lumbar spine mobility, and functional status in patients with unilateral lumbosacral radiculopathy.

Since the greatest amount of heat from the skin surface is lost through emission of IR rays, IRT is the method of choice that enables precise detection and visualisation of changes in skin temperature. ${ }^{17}$ By detecting changes in skin temperature, IRT can contribute to objective assessment of disease

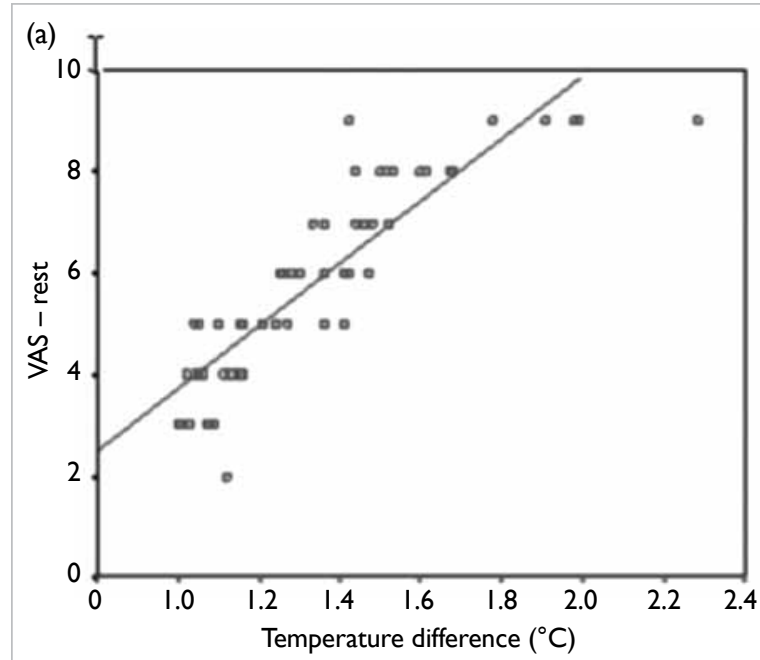

(b)

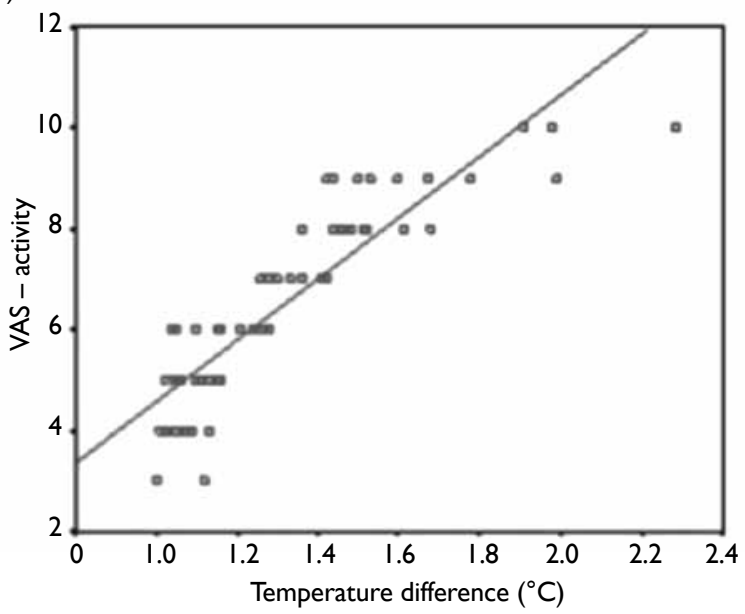

FIG I. The relationship between side-to-side temperature difference and pain intensity (a) at rest and (b) during active movement of the lumbar spine

Abbreviation: VAS = visual analogue scale 


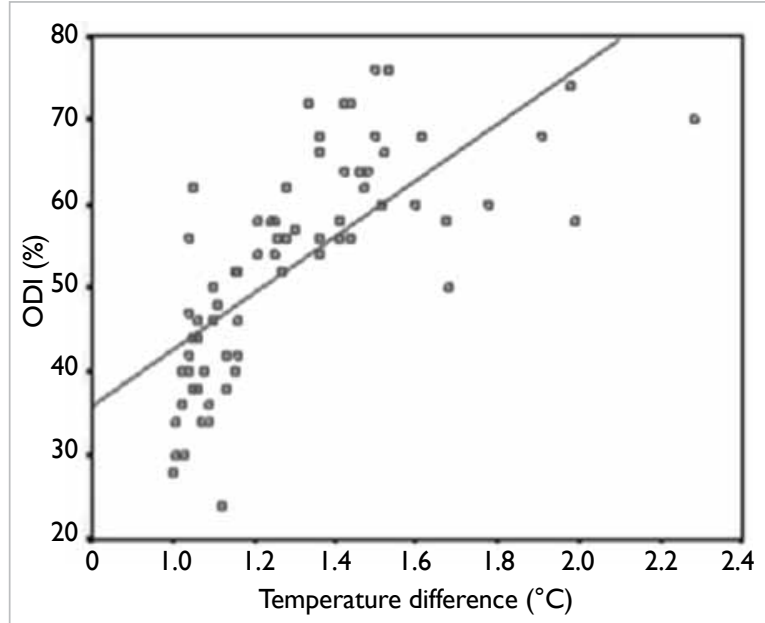

FIG 2. The relationship between side-to-side temperature difference and Oswestry Disability Index (ODI) that directly or indirectly affects the vascular microcirculation tonus that is regulated by the autonomous nervous system. ${ }^{4,18}$ Some studies have shown the significance of thermography in the estimation of some painful conditions, including radiculopathy. ${ }^{4,8,10,18-20}$

Contrary to the methods that estimate radiculopathy on the basis of structural changes in the spine or changes in spinal nerve root function, IRT assesses radiculopathy based on a vasomotor dysfunction. Its advantage in comparison with other methods is its non-invasive, painless nature that does not expose the patient to ionising radiation and is also easy to use..$^{4,18,21}$ In cases of bilateral radiculopathy, false-negative results can be obtained because of false temperature symmetry. ${ }^{7,22}$

Our research focused on the lower extremities, similar to the majority of research on lumbosacral
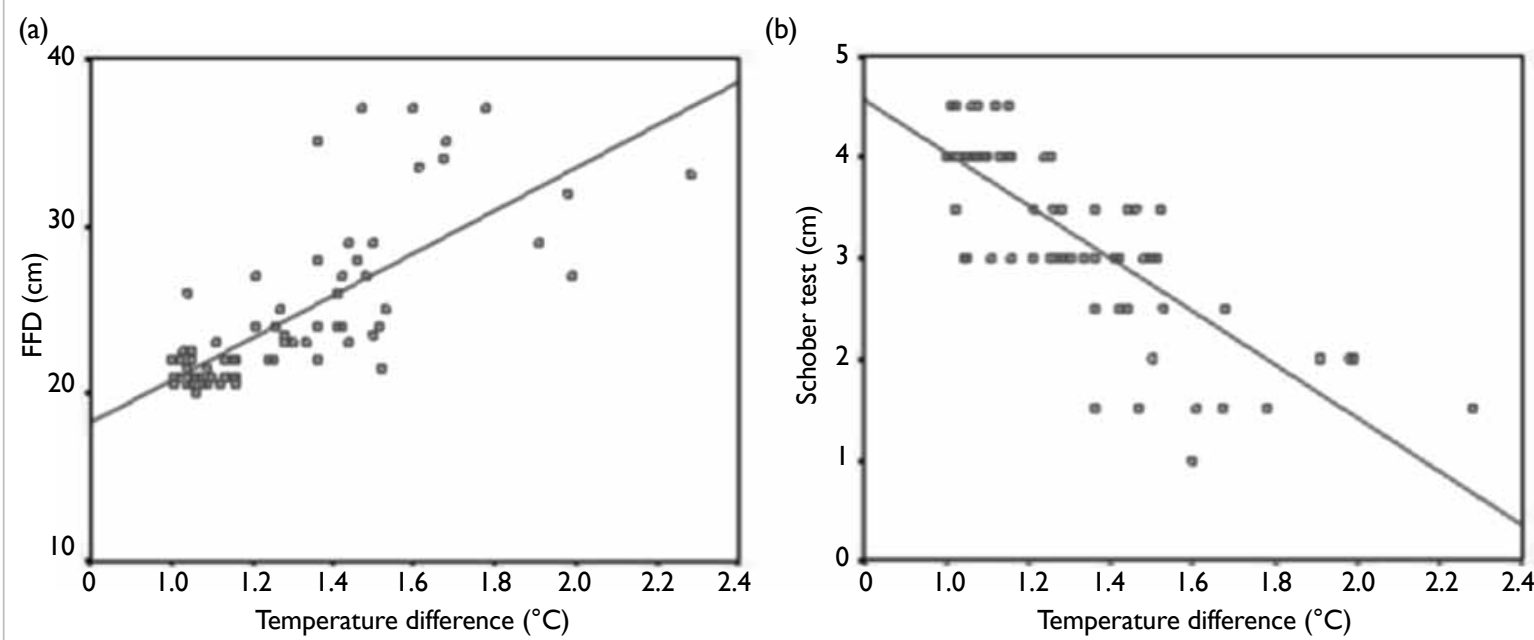

FIG 3. The relationship between side-to-side temperature difference and mobility of the lumbar spine: (a) fingertip-to-floor distance (FFD) and (b) Schober test
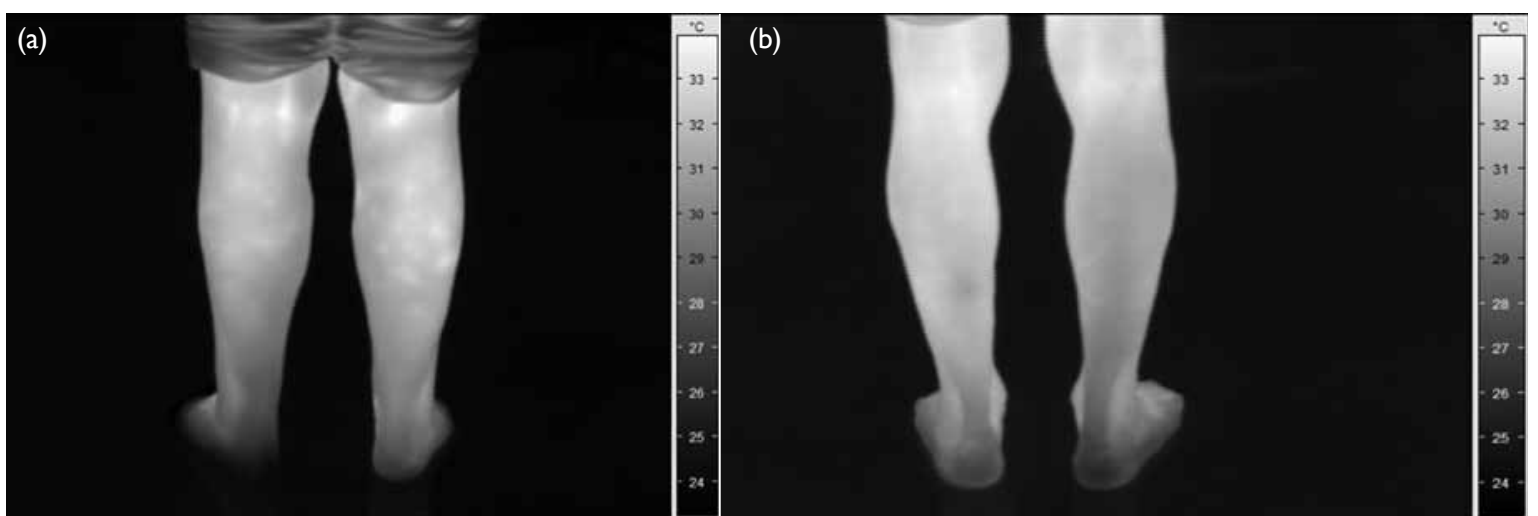

FIG 4. Thermograms of the lower extremities of patients

(a) A patient with $\Delta T$ - heel area $=2.08^{\circ} \mathrm{C}, \mathrm{VAS}$ - rest $=8$, and VAS - activity $=9$. (b) A patient with $\Delta T$ - heel area $=1.02^{\circ} \mathrm{C}$, VAS - rest $=4$, and VAS - activity $=5$

Abbreviation: VAS = visual analogue scale 
radiculopathy within the field of thermography. ${ }^{6,7,10,11}$ Detection and visualisation of skin temperature changes in the affected lower extremity was by IRT. This detects IR rays emitted from the surface of the body and then focuses and directs them by special lenses towards a photosensor that transforms the energy of the detected IR rays into electric impulses and then into a visible recording - a thermogram. The temperature emitted from the skin is thus visualised on the screen in the form of colour spectrum. ${ }^{23}$ Development of information technology has reduced the disadvantages of subjective estimation of the intensity of colouration on the thermogram. New-generation IR cameras show the temperature asymmetry as high-quality thermograms and enable a quantitative analysis. ${ }^{17,24}$

Qualitative analysis of the thermograms of patients showed regional hypothermia of the affected lower extremity, and has also been observed in other studies. $^{7,10,11}$ Regional hypothermia is considered a consequence of the sympathetic vasoconstrictor reflex that develops due to irritation of the dorsal root of the spinal nerve. ${ }^{7,22}$ Some authors describe hypothermia as muscle atrophy caused by denervation or inactivity. ${ }^{2,25}$

In our study, the regional thermal deficit of the affected lower extremity did not follow the distribution of a dermatome. A possible explanation for this is that blood supply to the skin of the lower extremities is quite different to the distribution of sensory nerves in the same region. ${ }^{2}$ Therefore, without additional information, it is not possible to use IRT to determine the level of disc herniation.

Maximum values of $\Delta \mathrm{T}$ have mostly been recorded at the heel or plantar region of the foot. This shows that vascular changes are more prominent in the distal regions of the affected extremity. Our results are similar to those obtained by Zaproudina et $\mathrm{al}^{22}$ who found a more significant correlation between pain intensity and temperature asymmetry in the plantar area of the foot in patients with low back pain (LBP).

The present study showed a statistically significant correlation between regional thermal deficit values of the affected lower extremity and radicular pain intensity. Our results are in accordance with the results obtained by other authors, who have observed a correlation between temperature asymmetry and radicular pain, and show that IRT can be effective in the objective differentiation of the presence or absence of pain..$^{5,7,9,10}$ In the present study, analysis of the correlation between the stated parameters demonstrated that the values of thermal deficit increase along with increased pain intensity (Fig 1). On the basis of this finding, it can be concluded that thermograms provide not only information about the existence of pain but also about pain intensity. This correlation has been explained as nociceptor excitation, the secondary consequence of which is vasoconstriction. ${ }^{26} \mathrm{~A}$ positive correlation between pain intensity and temperature asymmetry of the affected lower extremity was also found in research on patients with $\mathrm{LBP}^{22}$ although other researchers have found no clear correlation between temperature asymmetry and radicular pain intensity. ${ }^{2}$ These different results can be partially explained by the fact that the mentioned study established the diagnosis of unilateral radiculopathy only on the basis of clinical findings, while pathological findings of electrophysiological examination were present in only $43 \%$ of patients. In this study, MRI findings showed disc herniation in $86 \%$ of patients, but in $30 \%$ the herniation was central, and was not characterised by nerve compression and concomitant muscle denervation. ${ }^{2}$

It was also observed that higher values of thermal deficit are correlated with worse functional status of patients. The results of the ODI questionnaire showed that the examined patients had limited activities of daily living that was thought to be a result of conditioning by the presence of pain. The relationship of these parameters was also observed in the study by Zaproudina et $\mathrm{al}^{22}$ on patients with LBP.

The relationship between regional thermal deficit and spine mobility shows that spine mobility is reduced with increased values of thermal deficit. The correlation between abnormal changes in skin surface temperature and limited mobility has been previously observed in a study that included patients with pain syndrome in the pelvic-femoral region. ${ }^{27}$

Considering that the presence of pain can account for limited mobility of the lumbar region of the spine, as well as limited activities of daily living, the most significant of all correlations is the one between the regional thermal deficit of the affected lower extremity and radicular pain intensity.

The results of our study should be considered in light of the following limitations. The main limitation is the absence of a control group. Future research should address this. Another limitation is that circadian rhythm and psychological factors were not controlled. We believe that it has not significantly affected our results, because we did not analyse the absolute value of the temperature, but only the temperature difference between the two sides of the lower extremities.

\section{Conclusions}

Infrared thermography is a simple, non-invasive, and painless method that can be used to estimate neurovascular dysfunction in patients with unilateral lumbosacral radiculopathy. The correlation between thermal deficit and pain intensity is highly significant. Estimation of pain intensity by VAS is a subjective method, whereas determining the thermal deficit 
is objective. The information obtained on the basis of thermal deficit is significant as it provides an objective assessment of radicular pain intensity.

\section{Declaration}

All authors have disclosed no conflicts of interest.

\section{References}

1. Hsu PS, Armon C, Levin K. Lumbosacral radiculopathy: pathophysiology, clinical features, and diagnosis. Available from: http://cursoenarm.net/UPTODATE/contents/ mobipreview.htm?25/35/26161 ? source=HISTORY. Accessed 15 May 2015.

2. Ra JY, An S, Lee GH, Kim TU, Lee SJ, Hyun JK. Skin temperature changes in patients with unilateral lumbosacral radiculopathy. Ann Rehabil Med 2013;37:35563.

3. Lee JH, Lee SH. Physical examination, magnetic resonance image, and electrodiagnostic study in patients with lumbosacral disc herniation or spinal stenosis. J Rehabil Med 2012;44:845-50.

4. American Medical Association Council. Thermography in neurological and musculoskeletal conditions. Thermol 1987;2:600-7.

5. Feng T, Zhao P, Liang G. Diagnostic significance of topical image of infrared thermograph on the patient with lumbar intervertebral disc herniation-a comparative study on 45 patients and 65 normal control [in Chinese]. Zhongguo Zhong Xi Yi Jie He Za Zhi 1998;18:527-30.

6. Thomas D, Cullum D, Siahamis G, Langlois S. Infrared thermographic imaging, magnetic resonance imaging, CT scan and myelography in low back pain. Br J Rheumatol 1990;29:268-73.

7. Uematsu S, Jankel WR, Edwin DH, et al. Quantification of thermal asymmetry. Part 2: Application in low-back pain and sciatica. J Neurosurg 1988;69:556-61.

8. LaBorde TC. Thermography in diagnosis of radiculopathies. Clin J Pain 1989;5:249-53.

9. Ping Z, You FT. Correlation study on infrared thermography and nerve root signs in lumbar intervertebral disk herniation patient: a short report. J Manipulative Physiol Ther 1993;16:150-4. Erratum in: J Manipulative Physiol Ther 1993;16:560.

10. Takahashi Y, Takahashi K, Moriya H. Thermal deficit in lumbar radiculopathy. Correlations with pain and neurologic signs and its value for assessing symptomatic severity. Spine (Phila Pa 1976) 1994;19:2443-9.

11. Gillström P. Thermography in low back pain and sciatica.
Arch Orthop Trauma Surg 1985;104:31-6.

12. Scott J, Huskisson EC. Graphic representation of pain. Pain 1976;2:175-84.

13. Perret C, Poiraudeau S, Fermanian J, Colau MM, Benhamou MA, Revel M. Validity, reliability, and responsiveness of the fingertip-to-floor test. Arch Phys Med Rehabil 2001;82:1566-70.

14. Rezvani A, Ergin O, Karacan I, Oncu M. Validity and reliability of the metric measurements in the assessment of lumbar spine motion in patients with ankylosing spondylitis. Spine (Phila Pa 1976) 2012;37:E1189-96.

15. Fairbank JC, Pynsent PB. The Oswestry Disability Index. Spine (Phila Pa 1976) 2000;25:2940-52.

16. Schwartz RG. Guidelines for neuromusculoskeletal thermography. Thermol Int 2006;16:5-9.

17. Herry CL, Frize M. Quantitative assessment of painrelated thermal dysfunction through clinical digital infrared thermal imaging. BioMedical Engineering OnLine 2004. Available from: http://www.biomedical-engineeringonline.com/content/3/1/19. Accessed 15 May 2015.

18. Hooshmand H, Hashmi M, Phillips EM. Infrared thermal imaging as a tool in pain management-an 11 year study. Part I of II. Thermol Inter 2001;11:53-65.

19. Cojocaru MC, Cojocaru IM, Cojan Carlea NA, Cinteza D, Berteanu M. Infrared thermography-a tool for computer assisted research in rehabilitation medicine. Appl Mech Mater 2015;772:603-7.

20. Lahiri BB, Subramainam B, Jayakumar T, Philip J. Medical applications of infrared thermography: a review. Infrared Phys Technol 2012;55:221-35.

21. Nahm FS. Infrared thermography in pain medicine. Korean J Pain 2013;26:219-22.

22. Zaproudina N, Ming Z, Hänninen OO. Plantar infrared thermography measurements and low back pain intensity. J Manipulative Physiol Ther 2006;29:219-23.

23. Tkachenko YA, Golovanova M, Ovechkin AM. Clinical thermography [in Russian]. Nizhny Novgorod: Union of Western and Oriental Medicine; 1998.

24. Uematsu S, Edwin DH, Jankel WR, Kozikowski J, Trattner M. Quantification of thermal asymmetry. Part 1: Normal values and reproducibility. J Neurosurg 1988;69:552-5.

25. Hyun JK, Lee JY, Lee SJ, Jeon JY. Asymmetric atrophy of multifidus muscle in patients with unilateral lumbosacral radiculopathy. Spine (Phila Pa 1976) 2007;32:E598-602.

26. Conwell T. Distinct IR signatures result from neuropathic abnormalities of the limbs. Thermol Int 2013;23:34-5.

27. Gabrhel J, Popracová Z, Tauchmannová H, Chvojka Z. Thermal findings in pain syndromes of the pelvic-femoral region. Thermol Int 2013;23:157-63. 